\title{
Efficacy and safety of 3D print-assisted surgery for the treatment of pilon fractures: a meta-analysis of randomized controlled trials
}

Jianzhong Bai ${ }^{1 \dagger}$, Yongxiang Wang ${ }^{2 \dagger}$, Pei Zhang ${ }^{1}$, Meiying Liu', Peian Wang ${ }^{3}$, Jingcheng Wang ${ }^{2^{*}}$ and Yuan Liang ${ }^{2^{*}}$

\begin{abstract}
Objective: To compare the effects of 3D print-assisted surgery and conventional surgery in the treatment of pilon fractures.

Methods: PubMed, Embase, Web of Science, CNKI, CBM, and WanFang data were searched until July 2018. Two reviewers selected relevant studies, assessed the quality of studies, and extracted data. For continuous data, a weighted mean difference (WMD) and 95\% confidence intervals (Cl) were used. For dichotomous data, a relative risk (RR) and $95 \% \mathrm{Cl}$ were calculated as the summary statistics.

Results: There were seven randomized controlled trials (RCT) enrolling a total of 486 patients, 242 patients underwent 3D print-assisted surgery and 244 patients underwent conventional surgery. The pooled outcomes demonstrate 3D print-assisted surgery was superior to conventional surgery in terms of operation time [WMD $=-26.16,95 \% \mathrm{Cl}(-33.19$, $-19.14), P<0.001]$, blood loss [WMD $=-63.91,95 \% \mathrm{Cl}(-79.55,-48.27), P<0.001]$, postoperative functional scores $[\mathrm{WMD}=8.16,95 \% \mathrm{Cl}(5.04,11.29), P<0.001]$, postoperative visual analogue score $(\mathrm{VAS})[\mathrm{WMD}=-0.59,95 \% \mathrm{Cl}(-1.18$, $-0.01), P=0.05]$, rate of excellent and good outcome $[R R=1.20,95 \% \mathrm{Cl}(1.07,1.34), P=0.002]$, and rate of anatomic reduction $[R R=1.35,95 \% \mathrm{Cl}(1.19,1.53), P<0.001]$. However, there was no significant difference between the groups regarding the rate of infection $[R R=0.51,95 \% \mathrm{Cl}(0.20,1.31), P=0.16]$, fracture union time $[\mathrm{WMD}=-0.85,95 \%$ $\mathrm{Cl}(-1.79,0.08), P=0.07]$, traumatic arthritis $[\mathrm{RR}=0.34,95 \% \mathrm{Cl}(0.06,2.09), P=0.24]$, and malunion $[\mathrm{RR}=0.34$, $95 \% \mathrm{Cl}(0.06,2.05), P=0.24]$.

Conclusions: Our meta-analysis demonstrates 3D print-assisted surgery was significantly better than conventional surgery in terms of operation time, blood loss, postoperative functional score, postoperative VAS, rate of excellent and good outcome, and rate of anatomic reduction. Concerning postoperative complications, there were no significant differences between the groups.
\end{abstract}

Keywords: Three-dimensional, 3D printing, Computer-assisted, Pilon fractures, Surgery

\footnotetext{
* Correspondence: wangjcyangzhou@163.com; 464156241@qq.com

${ }^{\dagger}$ Jianzhong Bai and Yongxiang Wang contributed equally to this work.

${ }^{2}$ Clinical Medical College, Yangzhou University, Yangzhou 225001, China

Full list of author information is available at the end of the article
}

(C) The Author(s). 2018 Open Access This article is distributed under the terms of the Creative Commons Attribution 4.0 International License (http://creativecommons.org/licenses/by/4.0/), which permits unrestricted use, distribution, and reproduction in any medium, provided you give appropriate credit to the original author(s) and the source, provide a link to the Creative Commons license, and indicate if changes were made. The Creative Commons Public Domain Dedication waiver (http://creativecommons.org/publicdomain/zero/1.0/) applies to the data made available in this article, unless otherwise stated. 


\section{Introduction}

Pilon fractures are usually caused by high energy trauma, accompanied by multiple metaphyseal fragments, displaced intra-articular comminution, and severe soft tissue injuries: this is a substantial problem for experienced orthopedic surgeons [1, 2]. The purpose of surgical treatment is an anatomic reduction of the articular fragments, firm fixation, and early functional exercise [3, 4]. However, postoperative complications seriously affect the effects of surgery, such as severe pain, skin necrosis, malunion, implant failure, joint stiffness, and even posttraumatic arthritis $[5,6]$. Therefore, it is necessary to seek a new method to reduce postoperative complications and improve the outcomes of surgery.

Recently, 3D printing technology has developed rapidly in the medical field [7], primarily using a 3D digital model to build a 1:1 fracture model based on the patient's imaging data. Furthermore, surgeons can perform a pre-operation to identify unforeseen problems during surgery that could assist in formulation of preoperative planning, simulation of the surgical procedure, and achievement of better surgical outcomes [8]. However, there are no relevant meta-analyses or clinical guides to assess the effects of $3 \mathrm{D}$ print-assisted surgery for the treatment of pilon fractures. It is unclear whether 3D print-assisted surgery can significantly improve the postoperative outcomes of patients compared to conventional surgery. Therefore, we performed this meta-analysis to identify the issue and then provided a better treatment strategy for clinicians.

\section{Methods}

We carried out this meta-analysis strictly according to the Preferred Reporting Items for Systematic Reviews and Meta-Analysis (PRISMA) statement [9] and the Cochrane Collaboration guidelines.

\section{Search strategy}

PubMed, Embase, Web of Science, CNKI, CBM, and WanFang data were searched until July 2018. Besides, we manually searched the reference lists of all included relevant publications to identify potential studies. We considered articles published in any language. The following keywords were adopted in the database search: "pilon fractures," "3D printing," "computer-assisted," and "surgery." The Boolean operators were used to combine them.

\section{Study selection and eligibility criteria}

The inclusion criteria were as follows: (1) pilon fractures diagnosed by validated screening or diagnostic instruments, (2) the study compared 3D print-assisted surgery with conventional surgery for the treatment of pilon fractures, (3) the study design was randomized controlled trial
(RCT), (4) Chinese articles included must have title and abstract in English, and (5) the study contained at least one of the following indicators: operation time, blood loss, postoperative functional score, rate of excellent and good outcome, rate of anatomic reduction, or postoperative complications. The exclusion criteria were as follows: (1) other types of fractures, (2) studies provided insufficient data, and (3) case report, review, commentary, or study only included an abstract (Table 1).

\section{Data extraction}

Two reviewers performed data extraction. The following information was extracted from eligible studies: author, year, study design, sample size, age, postoperative outcomes, and classification of pilon fractures. Any disagreements were resolved by discussion to reach a consensus. All extracted data were entered into a predefined standardized Excel (Microsoft Corporation, USA) file carefully.

\section{Quality assessment}

We evaluated the quality of the RCTs according to the methods of the 12-item scale [10]. Each item was scored "Yes," "Unclear," or "No." A study with a score of more than 7 "Yes" response was considered as of high quality, 5-7 was considered as of moderate quality, and 0-4 was considered as of low quality.

\section{Statistical analysis}

Statistical analyses were performed by using Revman 5.3 software. For continuous outcomes, weighted mean difference (WMD) with 95\% CI was used. For dichotomous data, relative risk (RR) with $95 \%$ CI was calculated as the summary statistics. $P \leq 0.05$ was regarded as statistically significant. The $I^{2}$ statistic assessed statistical heterogeneity, with $I^{2}$ value more than $50 \%$ indicating significant heterogeneity, the random-effects model was used to do the analysis; otherwise, the fixed-effects model was used. In addition, sensitivity analyses were conducted to insure the accuracy of the outcomes.

\section{Results \\ Search result}

A total of 84 potentially relevant references were found. We removed 39 duplicate studies. By scanning the titles and abstracts, 37 studies were excluded from the analysis. After full texts were carefully read according to eligibility, one study was excluded because it was not an RCT [11]. Finally, seven studies were included in quantitative synthesis [12-18]. The characteristics of all included studies are shown in Table 1. Details of the study selection process are shown in Fig. 1. 
Table 1 Characteristics of included studies

\begin{tabular}{|c|c|c|c|c|c|c|}
\hline Studies & Year & Study year & Groups & Sample size & Age \pm mean (year) & Pilon fracture classification \\
\hline \multirow[t]{2}{*}{ Huang et al. } & 2015 & $2008-2013$ & $3 \mathrm{D}$ & 31 & 48.6 & RA: | 9, || 12, ||| 10 \\
\hline & & & C & 30 & 48.6 & RA: | 7, || 15, ||| 8 \\
\hline \multirow[t]{2}{*}{ Tang et al. } & 2015 & 2012-2014 & $3 \mathrm{D}$ & 32 & $38.4 \pm 2.8$ & RA: I| 12, III 20 \\
\hline & & & C & 32 & $37.2 \pm 2.4$ & RA: \|| 15, III 17 \\
\hline \multirow[t]{2}{*}{ Fan et al. } & 2016 & 2014-2015 & $3 D$ & 50 & $43.5 \pm 3.5$ & RA: II 20, III 30 \\
\hline & & & C & 50 & $43.5 \pm 3.5$ & RA: || 21, III 29 \\
\hline \multirow[t]{2}{*}{ Li et al. } & 2016 & 2013-2014 & $3 D$ & 30 & $34.8 \pm 6.0$ & $\mathrm{AO}: 13 \mathrm{C} 2,17 \mathrm{C} 3$ \\
\hline & & & C & 30 & $35.8 \pm 6.2$ & $\mathrm{AO}: 12 \mathrm{C2}, 18 \mathrm{C} 3$ \\
\hline \multirow[t]{2}{*}{ Gu et al. } & 2017 & $2011-2015$ & $3 \mathrm{D}$ & 36 & $38.9 \pm 5.9$ & RA: || 15, III 21 \\
\hline & & & C & 36 & $39.6 \pm 5.5$ & RA: || 12, II| 24 \\
\hline \multirow[t]{2}{*}{ Ou et al. } & 2017 & $N R$ & $3 D$ & 18 & $37.4 \pm 3.7$ & RA: I| 10, III 8 \\
\hline & & & C & 18 & $38.4 \pm 3.5$ & RA: \| 9, III 9 \\
\hline \multirow[t]{2}{*}{ Zheng et al. } & 2018 & 2013-2016 & $3 \mathrm{D}$ & 45 & $41.2 \pm 9.3$ & $\mathrm{AO}: 5 \mathrm{Cl}, 14 \mathrm{C2}, 26 \mathrm{C} 3$ \\
\hline & & & C & 48 & $42.5 \pm 9.0$ & AO: 8 C1, 17 C2, 23 C3 \\
\hline
\end{tabular}

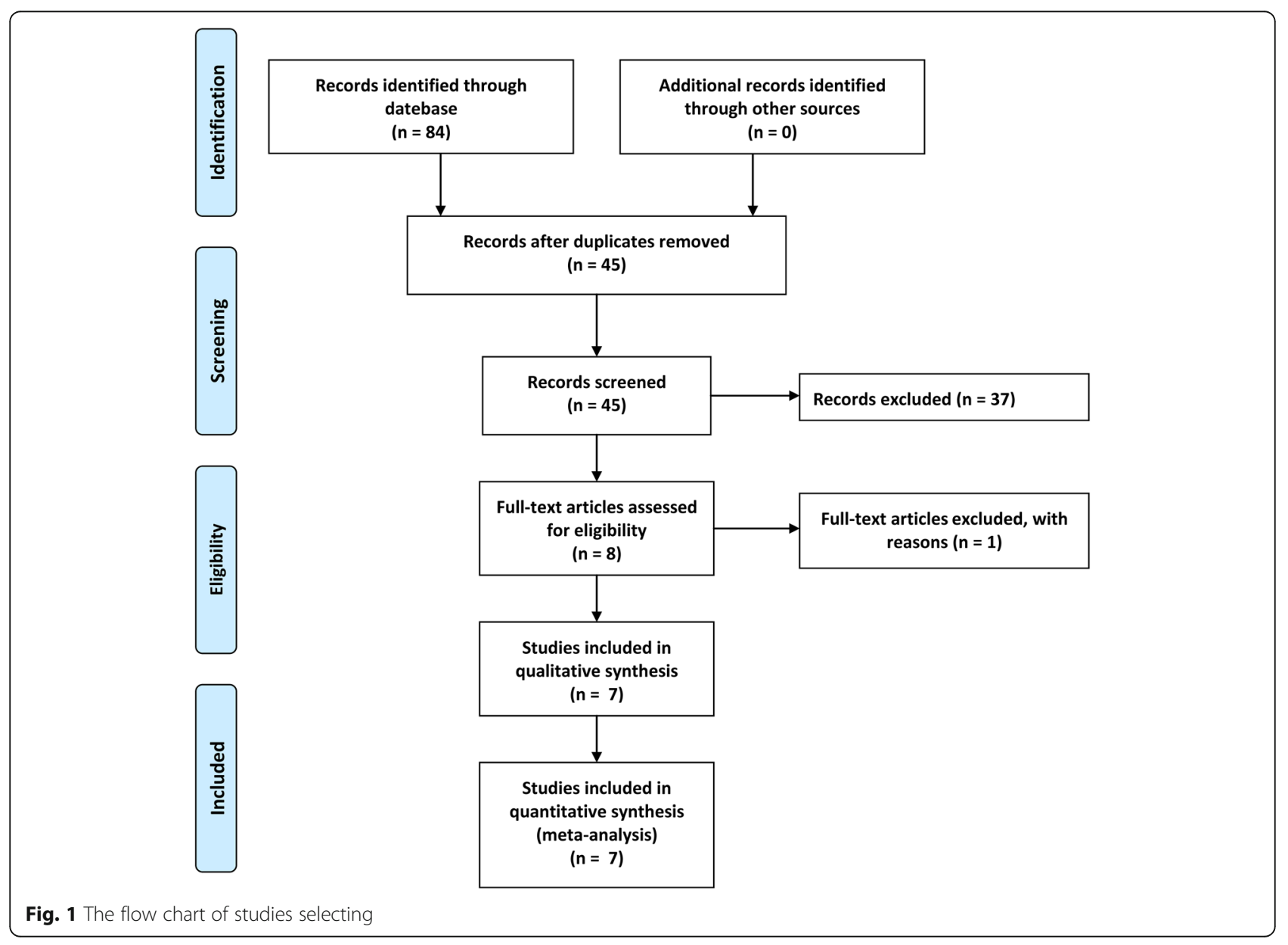




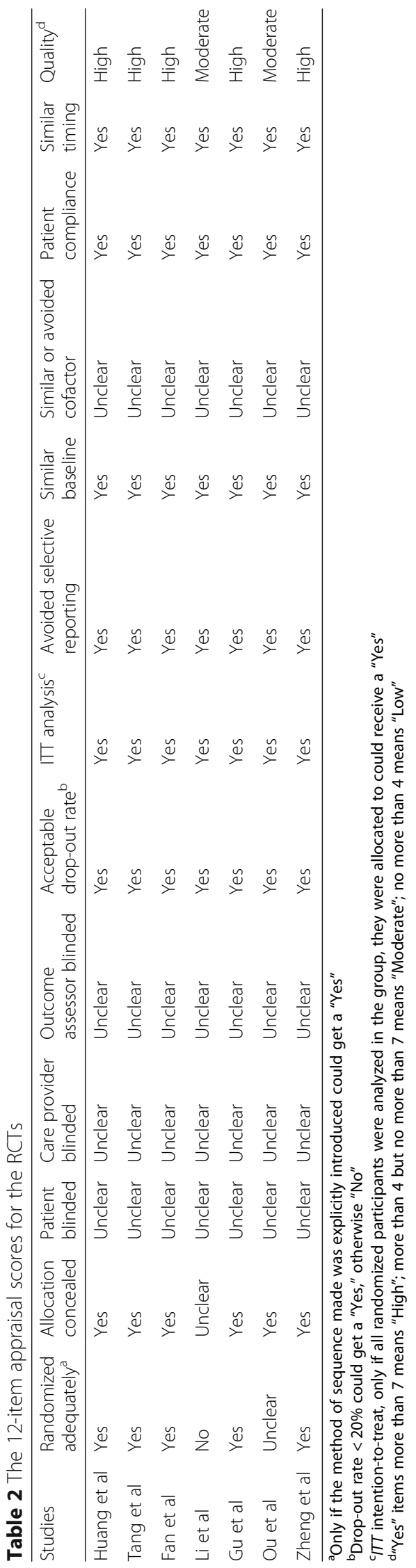




\section{Quality assessment}

The details of the quality assessment of included studies are shown in Table 2. Five studies [12, 13, 15, 17, 18] were of high quality, and two studies $[14,16]$ were of moderate quality. The randomization methods were explicitly introduced in five studies [12, 13, 15, 17, 18]. No study reported blinding of outcome assessment. However, all of the included studies were reported with complete outcome data.

\section{Clinical outcomes}

\section{Operation time (mins)}

The operation time was reported in seven studies [12$18]$, and the pooled results demonstrated that the 3D print-assisted surgery group had a significantly shorter operation time than did the conventional surgery group [WMD $=-26.16,95 \%$ CI $(-33.19,-19.14), P<0.001$, $I^{2}=95 \%$, Fig. 2].

\section{Blood loss ( $\mathrm{ml}$ )}

Five studies [12, 13, 15-17] provided available data, and the pooled results demonstrated that the 3D print-assisted surgery group had a significantly less blood loss than the conventional surgery group [WMD $=-63.91,95 \% \mathrm{CI}$ (-79.55, -48.27), $P<0.001, I^{2}=93 \%$, Fig. 3].

\section{Postoperative functional scores}

Five studies [12, 13, 15-17] provided available data, and the pooled results demonstrated that the $3 \mathrm{D}$ print-assisted surgery group had a significantly higher functional score than did the conventional surgery group $[\mathrm{WMD}=8.16$, $95 \%$ CI $(5.04,11.29), P<0.001, I^{2}=64 \%$, Fig. 4].

\section{The rate of excellent and good outcomes}

Four studies $[14,15,17,18]$ provided available data, and the pooled results demonstrated that the 3D print-assisted surgery group had a higher rate of excellent and good outcomes than did the conventional surgery group $[R R=1.20,95 \% \mathrm{CI}(1.07,1.34), P=0.002$, $I^{2}=0 \%$, Fig. 5].

\section{The rate of anatomic reduction}

Three studies $[12,13,17]$ provided available data, and the pooled results demonstrated that the 3D print-assisted surgery group had a higher rate of anatomic reduction than the conventional surgery group $[R R=1.35,95 \% \mathrm{CI}$ (1.19, 1.53), $P<0.001, I^{2}=14 \%$, Fig. 5].

\section{Fracture union time (month)}

Three studies [15-17] provided available data concerning fracture union time, and the pooled outcomes demonstrated that there was no significant difference between the groups [WMD $=-0.85,95 \%$ CI $(-1.79$, 0.08), $P=0.07, I^{2}=96 \%$, Fig. 6$]$.

\section{Postoperative VAS}

Two studies [15, 17] provided available data, and the pooled outcomes demonstrated that 3D print-assisted surgery group had a lower VAS than the conventional surgery group $[\mathrm{WMD}=-0.59,95 \% \mathrm{CI}(-1.18,-0.01)$, $P=0.05, I^{2}=71 \%$, Fig. 6].

\section{Traumatic arthritis}

Two studies $[17,18]$ provided available data, and the pooled results demonstrated that two surgical methods have a similar effect regarding the rate of traumatic arthritis $[\mathrm{RR}=$ 0.34, 95\% CI (0.06, 2.09), $P=0.24, I^{2}=0 \%$, Fig. 7].

\section{Malunion}

Two studies $[17,18]$ provided available data regarding malunion, and the pooled results demonstrated there was no significant difference between the groups $[R R=$ 0.34, 95\% CI $(0.06,2.05), P=0.24, I^{2}=3 \%$, Fig. 7].

\section{Infection rate}

Three studies $[14,15,17]$ provided available data concerning infection rate, and the pooled results demonstrated

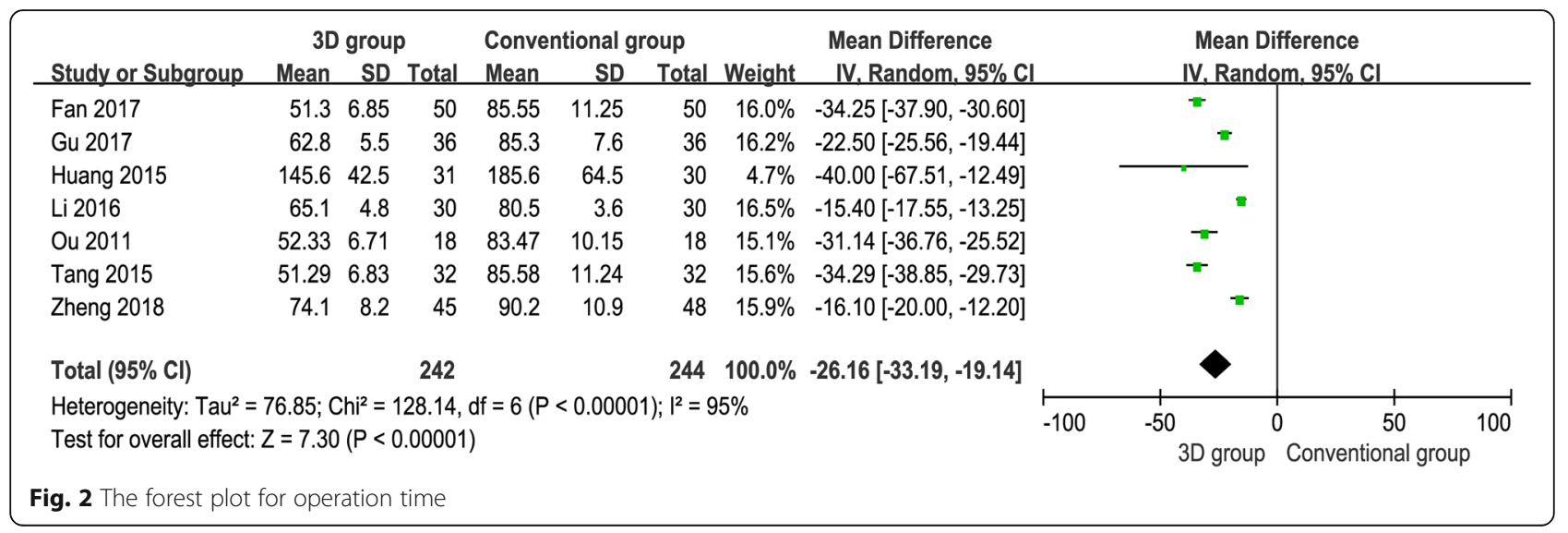




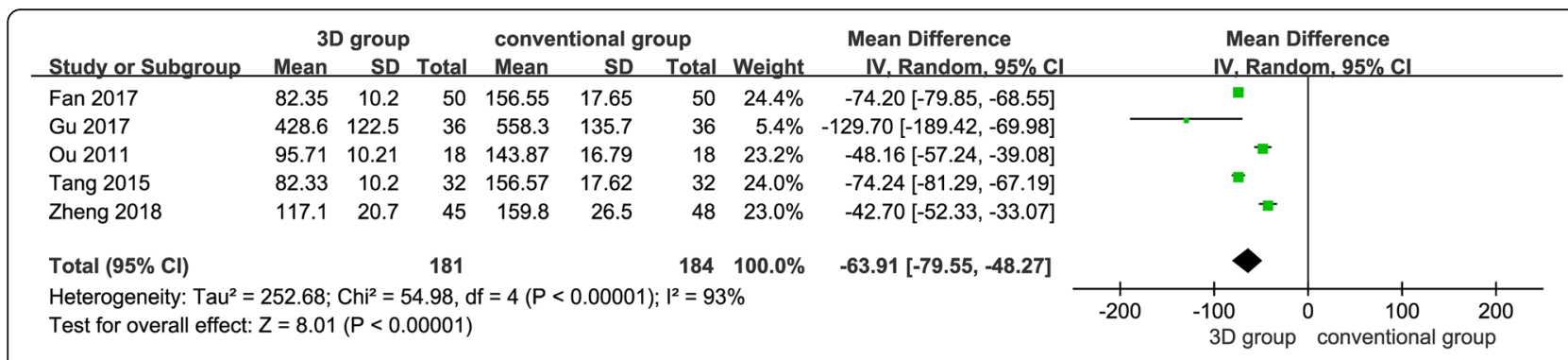

Fig. 3 The forest plot for blood loss

that the 3D print-assisted surgery group had a lower infection rate than the conventional surgery group, but there is no significant difference between the groups $[R R=0.51$, $95 \%$ CI $(0.20,1.31), P=0.16, I^{2}=0 \%$, Fig. 7].

\section{Sensitivity analysis}

Due to fewer studies were included in some outcomes, we only performed sensitivity analysis on the results of operation time, blood loss, and postoperative functional score. These outcomes all remained stable after the exclusion of each study once a time.

\section{Discussion}

\section{Main findings}

Our meta-analysis demonstrated that the 3D printassisted surgery was significantly better than the conventional surgery concerning operation time, blood loss, postoperative functional score, postoperative VAS, rate of excellent and good outcome, and rate of anatomic reduction. Although the 3D print-assisted surgery group had a lower incidence rate than the conventional surgery group concerning infection rate, traumatic arthritis, and malunion, there were no significant differences between the groups.

It is approximated that pilon fractures constitute $1 \%$ of all lower extremity fractures and $5-10 \%$ of tibia fractures [19]. Most pilon fractures require surgery, and the main purpose is to firmly fix the intra-articular fragments and restore the length and alignment, allowing for earlier weight bearing and functional exercise [20]. Orthopedists usually formulate surgical plans based on X-ray, $\mathrm{CT}$, or other examination outcomes with conventional surgery [21]. However, pilon fractures are severely comminuted fractures, and the ankle joints are often accompanied by severe collapse and loss of bone. Conventional imaging outcomes cannot directly display the specific shape of the fracture, and even sometimes omit occult fractures. The surgeon continues surgery based on clinical experience when the intraoperative condition is not consistent with the expected situation during surgery, which possibly leads to change of the surgical plan, prolong the operation time, increase the blood loss, aggravate the soft tissue injury, and even cause the failure of the operation. Therefore, it is critical for surgeons to perform a pre-surgery based on 3D printing model. They can predict the problems that may be encountered during the operation, such as the optimal surgical approach, matched implant. Therefore, this surgical method shortens the operation time and improves the effects of surgery [22]. In addition, the surgeon can adequately communicate with patients using this vivid fracture model [23].

Although 3D printing technology promotes the development of orthopedic surgery, it has some certain limitations, such as increasing the economic burden of patients. Besides, 3D printing technology requires high

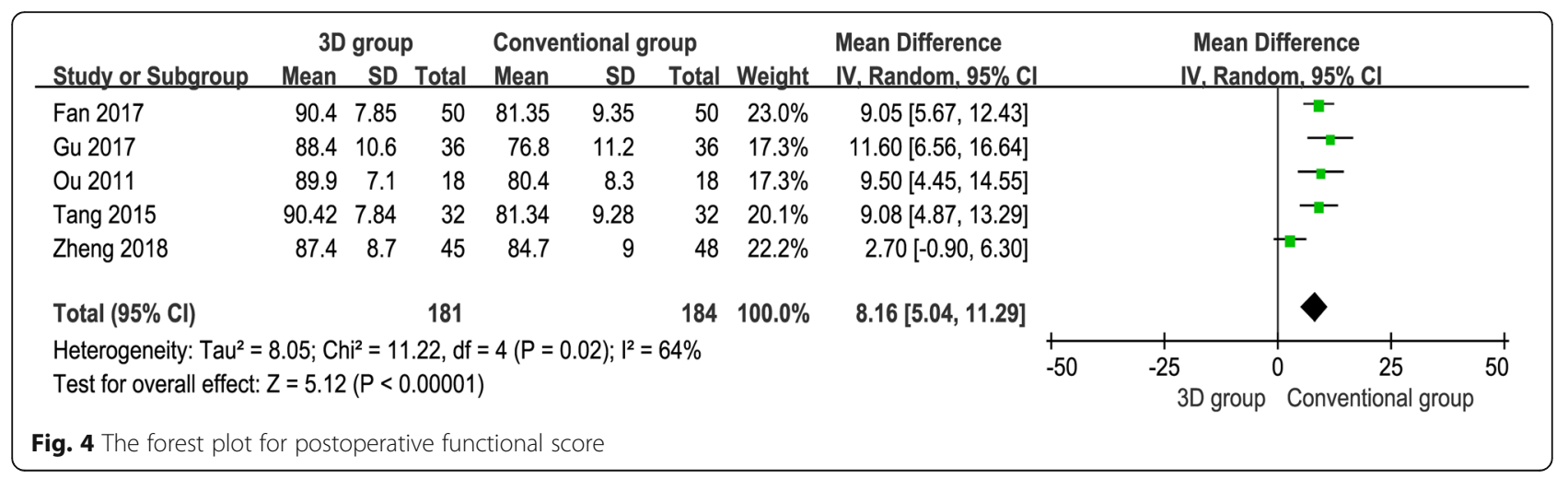




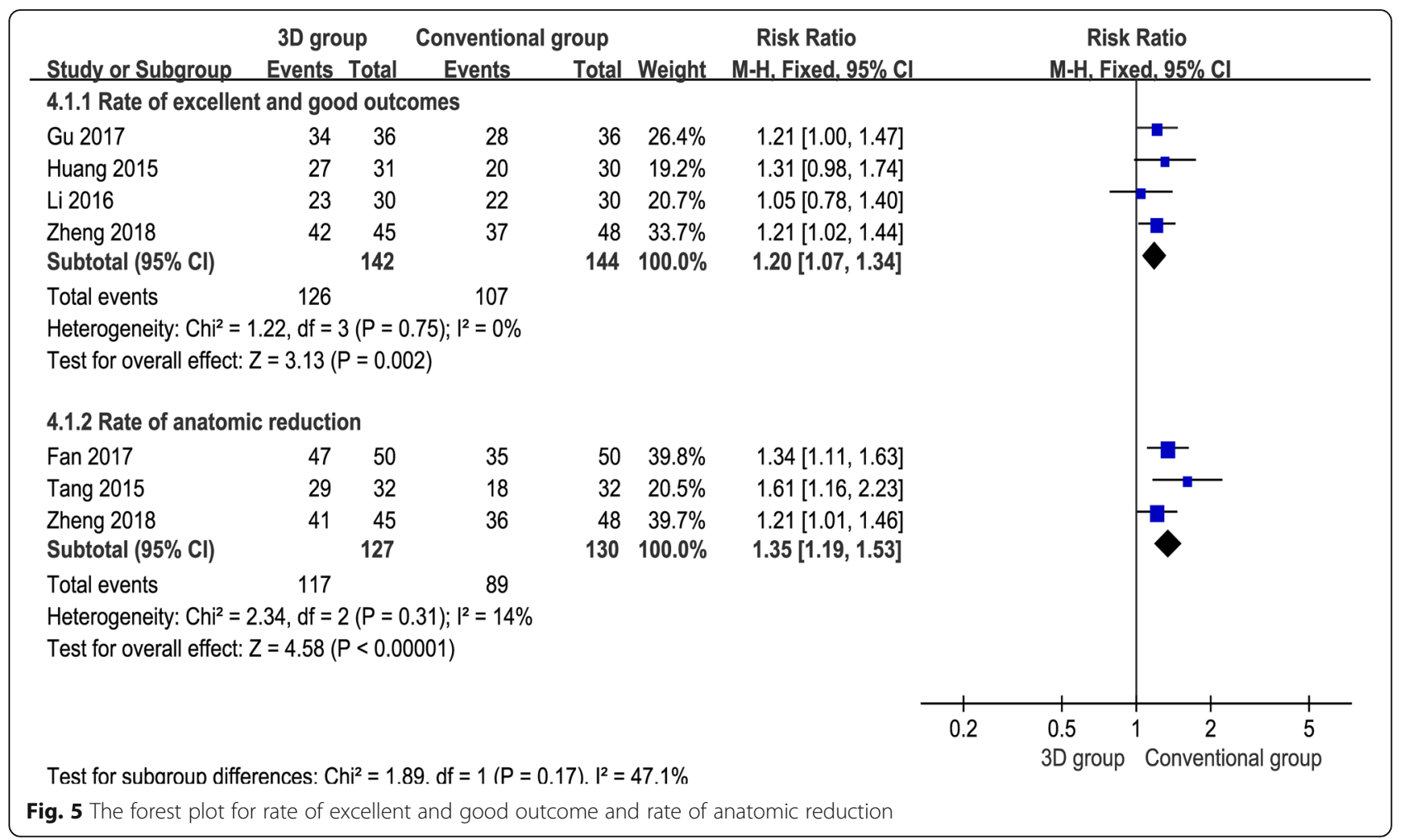

requirements, complicated operating technique, and expensive $3 \mathrm{D}$ printing instruments that limit the promotion of this technology. Furthermore, for some complex intra-articular fractures, reconstruction and printing of 3D models increase preoperative preparation time, so this technique is not suitable for emergency surgery. Another disadvantage of $3 \mathrm{D}$ printing technology is that it cannot be displayed for soft tissues, such as vasculars and nerves.

Currently, there remains a lack of attention to the treatment of pilon fractures with 3D print-assisted surgery, and to the best of our knowledge, there has been no meta-analysis of the comparison between the methods. Our meta-analysis demonstrated that 3D print-assisted

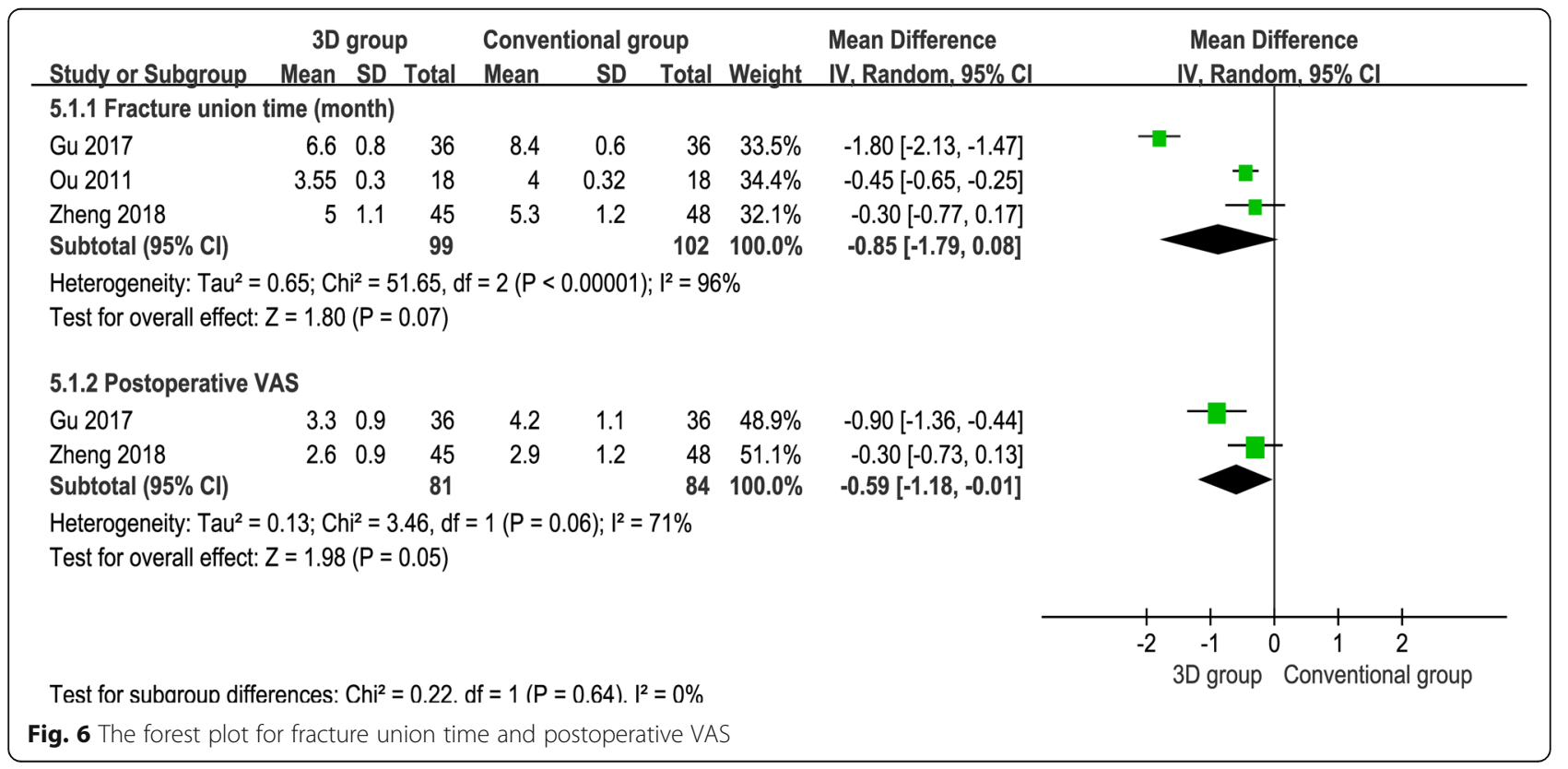




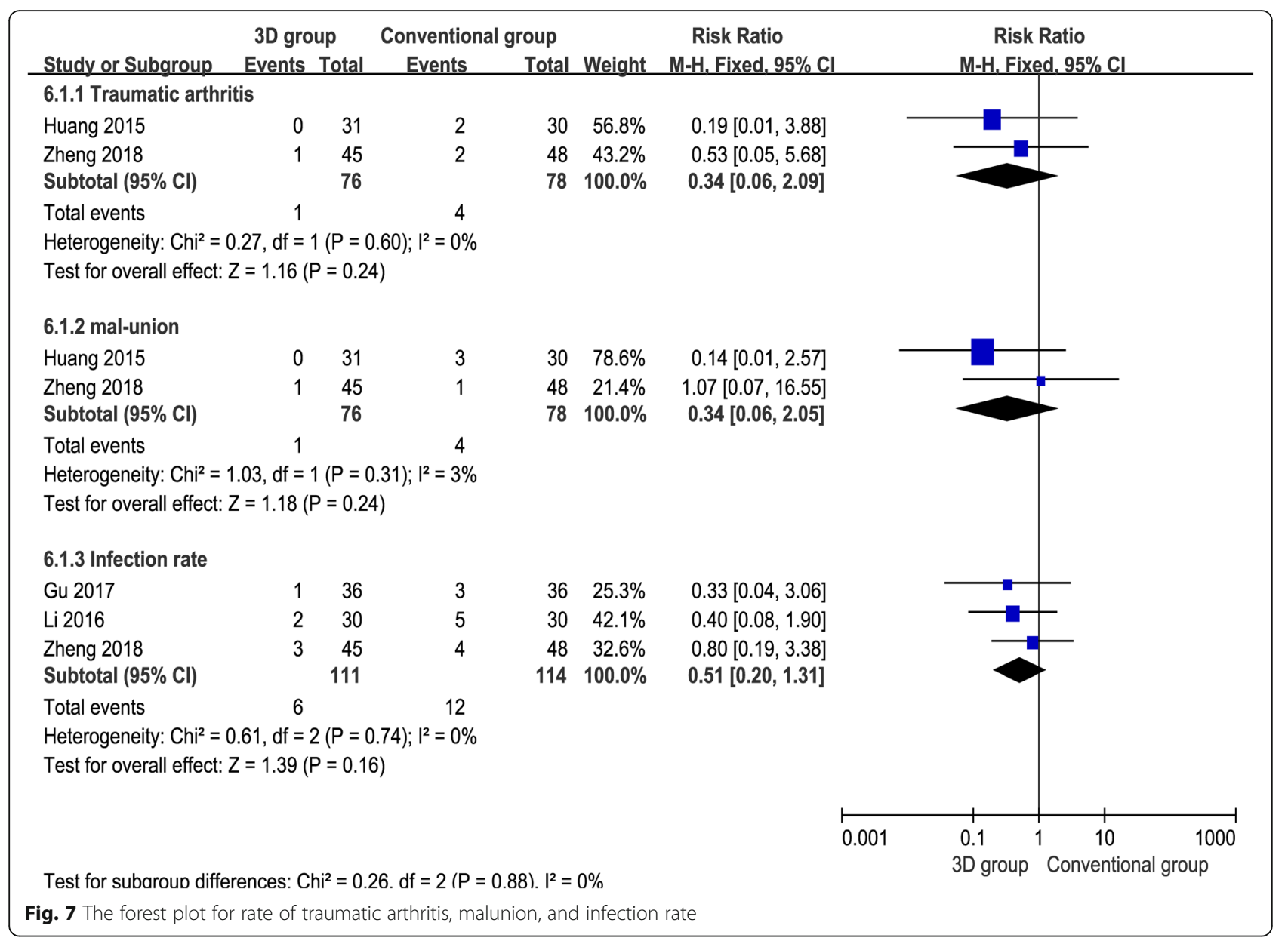

surgery has advantages in terms of operation time, blood loss, and functional scores, similar to the previous studies [12-17]. However, both groups had similar infection rates, the pooled results consistent with the results of $\mathrm{Li}$ et al. and Zheng et al. $[14,17]$. In theory, 3D print-assisted surgery has shorter operative time and less blood loss, so the infection rate should be lower, which requires a large sample of RCTs to update this conclusion.

\section{Limitations}

Although this was the first meta-analysis to compare 3D print-assisted surgery with conventional surgery for the treatment of pilon fractures based on seven RCTs, there was a small sample size of included studies, possibly affecting the accuracy of our conclusions. Besides, this meta-analysis had a higher heterogeneity in some pooled outcomes; unequal levels of regional medical care, varying follow-up time, different levels of the operators, and degree of patient injury may contribute it.

\section{Conclusions}

Our meta-analysis demonstrates 3D print-assisted surgery was significantly better than the conventional surgery in terms of operation time, blood loss, postoperative functional score, postoperative VAS, rate of excellent and good outcome, and rate of anatomic reduction. Although the $3 \mathrm{D}$ print-assisted surgery group had a lower incidence rate than the conventional surgery group concerning infection rate, traumatic arthritis, and malunion, there were no significant differences between the groups. Future large-volume, well-designed RCTs with extensive follow-up are awaited to confirm and update the findings of this analysis.

\section{Abbreviations}

3D: Three-dimensional; Cl: Confidence interval; RCT: Randomized controlled trial; RR: Relative risk; VAS: Visual analogue score; WMD: Weighted mean difference

\section{Acknowledgements}

We thank the authors of the included studies for their help.

\section{Funding}

This study was supported by the project foundation of Northern Jiangsu People's Hospital: (yzucms201623), (fcjs201715); National Natural Science Foundation of China: (81772332); Natural Science Foundation of Jiangsu Province (BK20141281), Special Foundation Project on the Prospective Study of Social Development in Jiangsu Province (BE2013911); Jiangsu Six Categories of Talent Summit Fund (WSW-133); Social Development of Science and Technology Research Project in Yangzhou (YZ2011082); and Jiangsu Province 333 talent Project (BRA2016159). 


\section{Availability of data and materials}

All data are fully available without restriction.

\section{Authors' contributions}

$J C W, Y L, Y X W$, and JZB conceived of the design of the study. JZB and PZ participated in the literature search, study selection, data extraction, and quality assessment. MYL and PAW performed the statistical analysis. JZB finished the manuscript. All authors read and approved the final manuscript.

\section{Ethics approval and consent to participate}

This article does not contain any studies with human participants or animals performed by any of the authors.

\section{Consent for publication}

Not applicable

\section{Competing interests}

The authors declare that they have no competing interests.

\section{Publisher's Note}

Springer Nature remains neutral with regard to jurisdictional claims in published maps and institutional affiliations.

\section{Author details}

'Dalian Medical University, Dalian 116044, Liaoning, China. ${ }^{2}$ Clinical Medical College, Yangzhou University, Yangzhou 225001, China. ${ }^{3}$ Heze Mudan People's Hospital, Heze 274000, China.

Received: 6 August 2018 Accepted: 17 October 2018

Published online: 12 November 2018

\section{References}

1. Bacon S, Smith WR, Morgan SJ, et al. A retrospective analysis of comminuted intra-articular fractures of the tibial plafond: open reduction and internal fixation versus external Ilizarov fixation. Injury. 2008;39(2):196-202.

2. Patterson MJ, Cole JD. Two-staged delayed open reduction and internal fixation of severe pilon fractures. J Orthop Trauma. 1999;13(2):85-91.

3. Bonar SK, Marsh JL. Unilateral external fixation for severe pilon fractures. Foot Ankle. 1993;14(2):57-64.

4. d'Heurle A, Kazemi N, Connelly C, et al. Prospective randomized comparison of locked plates versus nonlocked plates for the treatment of high-energy pilon fractures. J Orthop Trauma. 2015;29(9):420-3.

5. Sirkin M, Sanders R, DiPasquale T, Herscovici D Jr. A staged protocol for soft tissue management in the treatment of complex pilon fractures. J Orthop Trauma. 1999;13(2):78-84.

6. McFerran MA, Smith SW, Boulas HJ, Schwartz HS. Complications encountered in the treatment of pilon fractures. J Orthop Trauma. 1992:6(2):195-200.

7. Chana-Rodriguez F, Mananes RP, et al. 3D surgical printing and pre contoured plates for acetabular fractures. Injury. 2016:47(11):2507-11.

8. Azuma M, Yanagawa T, Ishibashi-Kanno N, et al. Mandibular reconstruction using plates prebent to fit rapid prototyping 3-dimensional printing models ameliorates contour deformity. Head Face Med. 2014;10:45.

9. Moher D, Liberati A, Tetzlaff J, Altman DG. Preferred reporting items for systematic reviews and meta-analyses: the PRISMA statement. Int J Surg. 2010;8(5):336-41.

10. Furlan AD, Pennick V, Bombardier C, van Tulder M. 2009 updated method guidelines for systematic reviews in the Cochrane Back Review Group. Spine. 2009;34(18):1929-41.

11. Zhang GY, Peng Y, Peng $L L$, et al. The clinical research of $3 D$ printing technology in treatment of high-energy Pilon fractures. J Minim Invasive Med. 2017;12(01):19-21.

12. Tang SH, Sun YJ, Zhao HM, et al. Clinical application of three-dimensional printing technique for the treatment of tibial Pilon fractures caused by high-energy. Orthop J China. 2015;23(22):2042-6.

13. Fan $L$. Clinical efficacy of $3 \mathrm{D}$ printing technology in the treatment of high energy Pilon fractures. World Latest Med Inf. 2016;16(19):27-8.

14. Li Y, Yuan Z. Application of rapid prototype and 3D printing in therapy of complex pilon fractures. Chin J Orthop trauma. 2016;18(1):42-6.

15. Gu H, Zhang Y, Lv XF, et al. 3D printing technology in applicatoin of tibial PILON fractures. Chin J Trauma Disabil Med. 2017;24:8-10.
16. Ou Yang HW, Zhao XD, Shi KM, et al. Clinical application of 3D printing technique in the treatment of high energy Pilon fracture. Chin Cont Med Edu. 2017;9(17):130-1.

17. Zheng W, Chen C, Zhang C, et al. The feasibility of 3D printing technology on the treatment of pilon fracture and its effect on doctor-patient communication. Biomed Res Int. 2018:8054698:1-10.

18. Huang J, Wang XP, Deng ZC, et al. Application of three-dimensional reconstruction using mimics software to repair of pilon fracture. I Clin Tis Eng Res. 2015;19(44):7167-71.

19. Vidyadhara S, Rao SK. llizarov treatment of complex tibial pilon fractures. Int Orthop. 2006;30(2):113-7.

20. Lomax A, Singh A, M NJ KCS. Complications and early results after operative fixation of 68 pilon fractures of the distal tibia. Scott Med J. 2015;60(2):79-84

21. Badillo K, Pacheco JA, Padua SO, Gomez AA, Colon E, Vidal JA. Multidetector CT evaluation of calcaneal fractures. Radiographics. 2011;31(1):81-92.

22. Bagaria V, Deshpande S, Rasalkar DD, Kuthe A, Paunipagar BK. Use of rapid prototyping and three-dimensional reconstruction modeling in the management of complex fractures. Eur J Radiol. 2011;80(3):814-20.

23. Yang L, Shang XW, Fan JN, et al. Application of 3D printing in the surgical planning of trimalleolar fracture and doctor-patient communication. Biomed Res Int. 2016;2016:2482086

\section{Ready to submit your research? Choose BMC and benefit from:}

- fast, convenient online submission

- thorough peer review by experienced researchers in your field

- rapid publication on acceptance

- support for research data, including large and complex data types

- gold Open Access which fosters wider collaboration and increased citations

- maximum visibility for your research: over $100 \mathrm{M}$ website views per year

At BMC, research is always in progress.

Learn more biomedcentral.com/submissions 